\title{
ОЦЕНКА ПОПУЛЯЦИОННОГО ИММУНИТЕТА К SARS-COV-2 НА ТЕРРИТОРИИ РОСТОВСКОЙ ОБЛАСТИ
}

А.Ю. Попова ${ }^{1,2}$, Е.Б. Ежлова ${ }^{1}$, А.А. Мельникова ${ }^{1}$, А.К. Носков ${ }^{3}$, Е.В. Ковалев ${ }^{4}$, Г.В. Карпущенко ${ }^{5}$, Л.В. Лялина ${ }^{6}$, В.С. Смирнов ${ }^{6}$, О.С. Чемисова ${ }^{3}$, А.В. Тришина ${ }^{3}$, Е.А. Березняк ${ }^{3}$, С.В. Воловикова ${ }^{3}$, С.И. Стенина ${ }^{3}$, Е.Г. Янович ${ }^{3}$, М.Г. Мелоян ${ }^{3}$, Н.Ю. Асмолова ${ }^{5}$, А.А. Усова ${ }^{5}$, С.С. Слись ${ }^{4}$, А.А. Тотолян ${ }^{6}$

${ }^{1}$ Федеральная служба по надзору в сфере защиты прав потребителей и благополучия человека, Москва, Россия

${ }^{2}$ Российская медицинская академия непрерывного профессионального образования, Москва, Российская Федерация

${ }^{3}$ Федеральное казенное учреждение здравоохранения «Ростовский-на-Дону противочумный институт» Федеральной службы по надзору в сфере защиты прав потребителей и благополучия человека, Ростов-на-Дону, Россия

${ }^{4}$ Управление Федеральной службы по надзору в сфере защиты прав потребителей и благополучия человека по Ростовской области, Ростов-на-Дону, Россия

${ }^{5}$ Федеральное бюджетное учреждение здравоохранения «Центр гигиены и эпидемиологии в Ростовской области», Ростов-на-Дону, Россия

${ }^{6}$ Федеральное бюджетное учреждение науки «Санкт-Петербургский научно-исследовательский институт эпидемиологии и микробиологии им. Пастера» Федеральной службы по надзору в сфере защиты прав потребителей и благополучия человека, Санкт-Петербург, Россия

\section{РЕЗЮМЕ}

В декабре 2019 года в городе Ухань (КНР) официально зарегистрирован первый случай новой коронавирусной инфекции (COVID-19), вызванной SARS-CoV-2. Пандемическое распространение COVID-19 оказало существенное влияние на общественное здравоохранение многих стран, и 30.01.2020 г. Всемирная организация здравоохранения объявила о введении режима чрезвычайной ситуации в области общественного здравоохранения, имеющей международное значение. Заболевания людей COVID-19 отмечены более чем в 200 странах.

В Российской Федерации к августу 2020 г. подтверждено более 850000 случаев заболевания, Ростовская область вошла в число десяти наиболее пораженных регионов России.

Распространение болезни во многом определяется состоянием популяционного иммунитета на определенной территории. Поскольку SARS-CoV-2 является новым патогеном, многие аспекты его передачи от человека к человеку и развития инфекционного процесса недостаточно охарактеризованы. Результаты массового серологического мониторинга могут составить основу для эпидемиологического прогноза, а также для разработки стратегии специфической профилактики болезни. 
Целью настоящего исследования были изучение специфического гуморального иммунного ответа и оценка уровня популяционного иммунитета к вирусу SARS-CoV-2 среди населения Ростовской области.

В исследовании приняли участие 3048 человек. Волонтеры, участвовавшие в исследовании, были распределены по семи возрастным группам. Проведенная оценка серопревалентности к SARS-CoV-2 жителей Ростовской области показала, что доля лиц с положительными результатами теста на антитела IgG к новому коронавирусу составила 16,5 \%, доля серопозитивных лиц в генеральной совокупности находится в пределах от 13,9\% до 19,1\% $(\mathrm{p}<0,05)$.

Достоверных гендерных различий в уровне серопревалентности не установлено, положительный результат зарегистрирован у 16,6\% обследованных женщин и 16,5\% мужчин. Установлен высокий уровень гуморального иммунитета к SARS-CoV-2 на фоне низких показателей заболеваемости у лиц в возрасте от 1 до 17 лет, что может свидетельствовать о доминировании бессимптомных форм болезни среди данной возрастной группы. Наибольший уровень серопозитивности выявлен среди дошкольников (33,6\%), учащихся (29,3\%), служащих (17,3\%), работников образования $(15,3 \%)$.

Ключевые слова: COVID-19, популяционный иммунитет, антитела IgG, Ростовская область.

Конфликт интересов. Авторы подтверждают отсутствие конфликта финансовых/нефинансовых интересов, связанных с написанием статьи.

Автор ответственный за переписку: Алексей Кимович Носков, e-mail: noskovepid@mail.ru. 


\section{ASSESSMENT OF POPULATION IMMUNITY TO SARS-COV-2 VIRUS IN THE ROSTOV REGION}

A.Yu. Popova, ${ }^{1,2}$, E.B. Ezhlova ${ }^{1}$, A.A. Melnikova ${ }^{1}$, A.K. Noskov ${ }^{3}$, E.V. Kovalev ${ }^{4}$, G.V. Karpushchenko $^{5}$, V.I. Lyalina ${ }^{6}$, V.S. Smirnov ${ }^{6}$, O.S. Chemisova ${ }^{3}$, A.V. Trishina ${ }^{3}$, E.A. Bereznyak $^{3}$, S.V. Volovikova ${ }^{3}$, S.I. Stenina ${ }^{3}$, E.G. Yanovich ${ }^{3}$, M.G. Meloyan ${ }^{3}$, N. Yu. Asmolova $^{5}$, A.A. Usova ${ }^{5}$, S.S. Slis ${ }^{4}$, A.A. Totolian ${ }^{6}$

${ }^{1}$ Federal Service for Surveillance on Consumer’ Rights Protection and Human Welfare, Moscow, Russian Federation.

${ }^{2}$ Russian Medical Academy of Continuing Professional Education, Moscow, Russian Federation

${ }^{3}$ Federal Service for Surveillance in the Sphere of Consumers Rights Protection and Human Welfare, the Federal Government Health Institution Rostov-on-Don Plague Control Research Institute, Rostov-on-Don, Russian Federation.

${ }^{4}$ Department Federal Service for Surveillance on Consumer Rights Protection and Human Welfare for the Rostov region, Rostov-on-Don, Russian Federation.

${ }^{5}$ Federal budgetary healthcare institution "Center of Hygiene and Epidemiology in the Rostov region", Rostov-on-Don, Russian Federation,

${ }^{6}$ Saint-Petersburg Pasteur Institute, St. Petersburg, Russian Federation.

\section{SUMMARY}

In December 2019, the first case of a new coronavirus infection (COVID-19) caused by SARS-CoV-2 was officially registered in the city of Wuhan, China. The pandemic spread of COVID-19 influenced public health in many countries, and on January 30th, 2020 the World Health Organization declared Public Health Emergency of International Concern. COVID-19 human diseases have been reported in more than 200 countries. In the Russian Federation by August 2020 more than 850,000 cases of the disease have been confirmed, with the Rostov region as one of the ten most affected regions in Russia.

The spread of the disease is largely determined by the state of population immunity in a certain area. Since SARS-CoV-2 is a new pathogen, many aspects of its person to person transmission as well as the development of the infectious process are poorly outlined. The outcome of mass serological monitoring can form the ground for an epidemiological forecast and specific disease prevention strategy.

Our research looks into specific humoral immune response and estimates the degree of population immunity to SARS-CoV-2 virus among the population of the Rostov region.

The study involved 3,048 people, the volunteers participating in the study were divided into seven age groups. The assessment of seroprevalence to SARS-CoV-2 in the Rostov region showed that the proportion of people positive for IgG to the new coronavirus was $16.5 \%$, the range of seropositive individuals in the general population is between $13.9 \%$ and $19.1 \%$ $(\mathrm{p}<0.05)$. 
There were no significant gender differences in the degree of seroprevalence with a positive result registered in $16.6 \%$ of women and $16.5 \%$ of men. A high level of humoral immunity to SARS-CoV-2 was established in individuals aged 1-17 in the light of low incidence rates, which may indicate the dominance of asymptomatic forms of the disease in this age group. The highest level of seropositivity was found in preschool children (33.6\%), students (29.3\%), employees (17.3\%), and education workers (15.3\%).

Key words: COVID-19, population immunity, antibody IgG, Rostov region.

Conflict of interest: The authors declare no conflict of interest.

Corresponding author: Aleksey K. Noskov, e-mail: noskov-epid@mail.ru. 


\section{Введение}

Коронавирусы - это семейство РНК-содержащих вирусов, включающее виды патогенные как для животных, так и человека. Впервые коронавирусы человека были выделены Tyrrell D.A. и Bynoe M.L. в 1965 г. от пациента с острым ринитом [1]. До 2002 года считалось, что у людей представители семейства Coronaviridae вызывают легкие по течению острые респираторные инфекции (ОРВИ) с поражением верхних дыхательных путей. Однако, в 2002-2003 гг. болезнь, вызванная SARS-CoV (TOPC, SARS), получила эпидемическое распространение среди населения 26 стран. По официальным данным в этот период заболело 8422 человека, в 916 случаях тяжелое течение болезни окончилось летальным исходом [2]. В 2012 году в Саудовской Аравии зарегистрирована болезнь, получившая название «Ближневосточный Респираторный Синдром» (БBPC, MERS). Всего в мире отмечено 2519 заболевших MERS с 866 летальными исходами. Эпидемическое распространение MERS отмечено в основном среди населения стран Аравийского полуострова [3].

В декабре 2019 года в городе Ухань (КНР) официально зарегистрирован первый случай новой коронавирусной инфекции (COVID-19), вызванной SARS-CoV-2. Пандемическое распространение COVID-19 оказало существенное влияние на общественное здравоохранение многих стран, и 30.01.2020 г. Всемирная организация здравоохранения объявила о введении режима чрезвычайной ситуации в области общественного здравоохранения, имеющей международное значение [4]. Заболевания людей COVID-19 отмечены более чем в 200 странах. Кумулятивный показатель числа заболеваний на 06 августа 2020 г. составил 872403 человек, из них 677365 выздоровело и 14638 умерло [https://coronavirus-monitor.ru/coronavirus-v-rossii/].

В Ростовской области первый случай новой коронавирусной инфекции (COVID-19) был выявлен 25 марта 2020 г. (13-ая календарная неделя) у вернувшейся из Таиланда жительницы г. Ростова-на-Дону с признаками болезни. Достоверный рост случаев COVID-19 приходится на 15-ю неделю, когда было зафиксировано 43 больных. Кривая заболеваемости жителей Ростовской области характеризуется максимальными показателями в период с 01 по 07 июня 2020 г. после чего отмечена нисходящая тенденция, пришедшаяся на период 06-12 июля 2020. После достижения минимальных значений вновь наметилась тенденция к росту заболеваемости, что, вероятно связано с отменой ряда противоэпидемических ограничений и начала сезона, сопровождающегося интенсивной миграцией туристов. В этой связи важно отметить точность выбора срока исследования серопревалентности, пришедшегося на 23 июня - 10 июля 2020 г. Можно полагать, что в период нисходящего тренда результаты исследования в максимальной 
степени отражают серопревалентность коренного населения, но не туристов, приехавших на отдых из других регионов. Не исключено, что тенденция к росту заболеваемости, наблюдающаяся с 13 июля 2020 г. потребует более пристального внимания к соблюдению мер противоэпидемической безопасности и представляет интерес исследование динамики популяционного иммунитета, формирующегося на фоне тенденции к росту заболеваемости.

Распространение болезни во многом определяется состоянием популяционного иммунитета на определенной территории. Приобретенный иммунитет формируется на уровне индивида путем естественного заражения патогеном, либо путем специфической иммунизации. Популяционный иммунитет слагается из иммунитета индивидуумов, и является косвенной защитой от эпидемического распространения болезни, когда в популяции существует достаточно большая доля иммунных лиц. Точка, в которой доля восприимчивых лиц ниже порога, необходимого для передачи инфекции, называется порогом популяционного иммунитета [5]. Порог популяционного иммунитета зависит от базового репродуктивного числа (R0). В своей простейшей форме популяционный иммунитет начинает действовать, когда доля лиц, обладающих иммунитетом к патогену, пересечет 1-1/R0. Нa R0 влияют многочисленные биологические, социальноповеденческие и экологические факторы. Часть этих факторов (инфекциозность возбудителя и ее продолжительность, механизм передачи возбудителя) являются биологическими константами, другие могут изменяться, например, плотность населения, социальная организация, возрастная структура, климатические условия, что может привести к искажению прогнозов и требует обоснованной интерпретации [6].

B период распространения SARS-CoV-2 различными исследователями базовое репродуктивное число вируса оценивалось в диапазоне от 2 до 6. Принимая оценку R0 равной 3 для SARS-CoV-2, порог популяционного иммунитета составляет приблизительно 67\% [7]. Поскольку SARS-CoV-2 является новым патогеном, многие аспекты его передачи от человека к человеку и развития инфекционного процесса недостаточно охарактеризованы. Необходим систематизированный серологический мониторинг, результаты которого могут составлять основу для эпидемиологического прогноза, а также для разработки стратегии специфической профилактики.

Целью настоящего исследования были изучение специфического гуморального иммунного ответа и оценка уровня популяционного иммунитета к вирусу SARS-CoV-2 среди населения Ростовской области. 


\section{Материалы и методы}

Работа проводилась в рамках первого этапа широкомасштабного проекта Роспотребнадзора по оценке популяционного иммунитета к SARS-CoV-2 у населения Российской Федерации, разработанного при участии ФБУН НИИ эпидемиологии и микробиологии им. Пастера с учетом протокола, рекомендованного ВОЗ. Исследование одобрено локальной Комиссией по биоэтике ФКУЗ Ростовский-на-Дону противочумный институт Роспотребнадзора и локальным этическим комитетом ФБУН НИИ эпидемиологии и микробиологии имени Пастера. Перед началом исследования все участники или их юридические представители были ознакомлены с целью, методикой исследования и подписали информированное согласие.

Отбор волонтеров для исследования проводили методом анкетирования и рандомизации путем случайной выборки. Критерием исключения была активная инфекция COVID-19 в момент анкетирования. Объем выборки определяли по формуле:

где:

$$
n=\frac{t^{2} \times p(1-p)}{m^{2}}
$$

n - объем выборки;

$\mathrm{t}-$ уровень точности (для 95\% ДИ $\mathrm{t}=1,96)$;

p - оценочная распространенность изучаемого явления (в данном случае при $50 \%=0,5$ );

$\mathrm{m}$ - допустимая ошибка - 5\% [8].

В исследовании приняли участие 3048 человек. Волонтеры, участвовавшие в исследовании, были распределены по 7 возрастным группам: 1-17 лет (n=404), от 18 до 29 лет (n=394), от 30 до 39 лет (n=453), от 40 до 49 лет $(n=512)$, от 50 до 59 лет (n=440), от 60 до 69 лет (n=453), 70 лет и старше (n=392).

Когорта волонтеров включала 899 мужчин и 2149 женщин. Соотношение мужчин и женщин составило 12,5\% и 70,5\%, т.е. участие женщин в исследовании было в 2,3 раза активнее.

Доля переболевших COVID-19 с диагнозом, установленным в лечебнопрофилактическом учреждении, составила 0,8\% (25 человек), а доля волонтеров, имевших признаки ОР3 в день обследования - 0,7\% (21 человек).

Взятие крови осуществляли из локтевой вены в количестве 3 мл. Исследование сывороток крови проводили с использованием набора реагентов для анализа сыворотки или плазмы крови человека на наличие специфических иммуноглобулинов класса $G$ к нуклеокапсиду вируса SARS-CoV-2 методом иммуноферментного анализа (Набор реагентов «ИФА анти-SARS-CoV-2 IgG») производства ФБУН «Государственный 
научный центр прикладной микробиологии и биотехнологии» в соответствии с инструкцией разработчика.

Статистическую обработку проводили с использованием программы Excel и сайта www.medstatistic.ru. Номинальные данные описывали с указанием абсолютных значений и процентных долей. Сравнение номинальных данных проводили при помощи критерия $\chi^{2}$ Пирсона. Значение критерия $X^{2}$ сравнивали с критическими значениями для соответствующего числа степеней свободы. В том случае, если полученное значение критерия $x^{2}$ превышало критическое, делали вывод о наличии статистической взаимосвязи. Корреляционную зависимость оценивали методом ранговой корреляции Спирмена. Для оценки достоверности различий показателей использовали уровень вероятности р $<0,05$.

\section{Результаты и обсуждение}

Проведенное исследование серопревалентности к SARS-CoV-2 жителей Ростовской области показало, что точечная оценка доли лиц положительных на IgG к новому коронавирусу, рассчитанная по исследуемой выборке, составила 16,5£0,67\% (табл. 1), доля серопозитивных лиц в генеральной совокупности находится в пределах от 13,9\% до $19,1 \%(\mathrm{p}<0,05)$.

Таблица 1/ Table 1

Серопревалентность населения Ростовской области к SARS-CoV-2

Seroprevalence of the population of the Rostov region to SARS-CoV-2

\begin{tabular}{|c|c|c|c|c|}
\hline \multirow{2}{*}{\multicolumn{2}{|c|}{$\begin{array}{l}\text { Возраст, годы } \\
\text { Age, years }\end{array}$}} & \multirow[t]{2}{*}{$\begin{array}{l}\text { Количество } \\
\text { исследованных проб } \\
\text { The number of } \\
\text { examined samples }\end{array}$} & $\begin{array}{l}\text { Из них IgG+ к SARS- } \\
\text { CoV-2 } \\
\text { Of these, IgG+ to } \\
\text { SARS-CoV-2 }\end{array}$ & $\begin{array}{l}\text { Количество } \\
\text { исследованных } \\
\text { проб } \\
\text { The number of } \\
\text { examined samples }\end{array}$ \\
\hline & & & $\begin{array}{l}\text { абс. } \\
\text { abs. }\end{array}$ & $\%, M \pm m$ \\
\hline \multicolumn{2}{|l|}{$1-17$} & 404 & 124 & $30,7 \pm 4,5$ \\
\hline \multirow{3}{*}{$\begin{array}{l}\text { в том числе } \\
\text { including }\end{array}$} & $1-6$ & 105 & 38 & $36,2 \pm 9,19$ \\
\hline & $7-13$ & 198 & 66 & $33,3 \pm 6,6$ \\
\hline & $14-17$ & 101 & 20 & $19,8 \pm 7,8$ \\
\hline \multicolumn{2}{|l|}{$18-29$} & 394 & 53 & $13,5 \pm 3,4$ \\
\hline \multicolumn{2}{|l|}{$30-39$} & 453 & 58 & $12,8 \pm 3,1$ \\
\hline \multicolumn{2}{|l|}{$40-49$} & 512 & 82 & $16,0 \pm 3,2$ \\
\hline \multicolumn{2}{|l|}{ 50-59 } & 440 & 64 & $14,5 \pm 3,3$ \\
\hline \multicolumn{2}{|l|}{$60-69$} & 453 & 74 & $16,3 \pm 3,4$ \\
\hline \multicolumn{2}{|l|}{$\geq 70$} & 392 & 49 & $12,5 \pm 3,3$ \\
\hline
\end{tabular}




\begin{tabular}{|l|l|l|l|}
\hline $\begin{array}{l}\text { Всего } \\
\text { Total }\end{array}$ & 3048 & 504 & $16,5 \pm 1,3$ \\
\hline
\end{tabular}

Следует отметить, что наиболее высокая доля положительных результатов

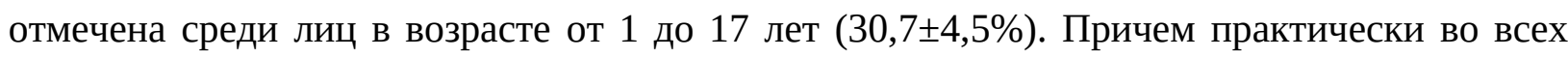
административных территориях, участвовавших в исследовании, уровень положительных проб в этой возрастной категории значительно превышал средний по муниципальному образованию. Так, в г. Волгодонске в этой возрастной категории населения зарегистрирован положительный результат в $33,3 \pm 5,8 \%$ случаев, в г. Каменск-

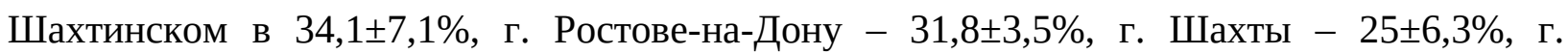
Таганроге $-19,4 \pm 4,8 \%$ (рис. 1 ).

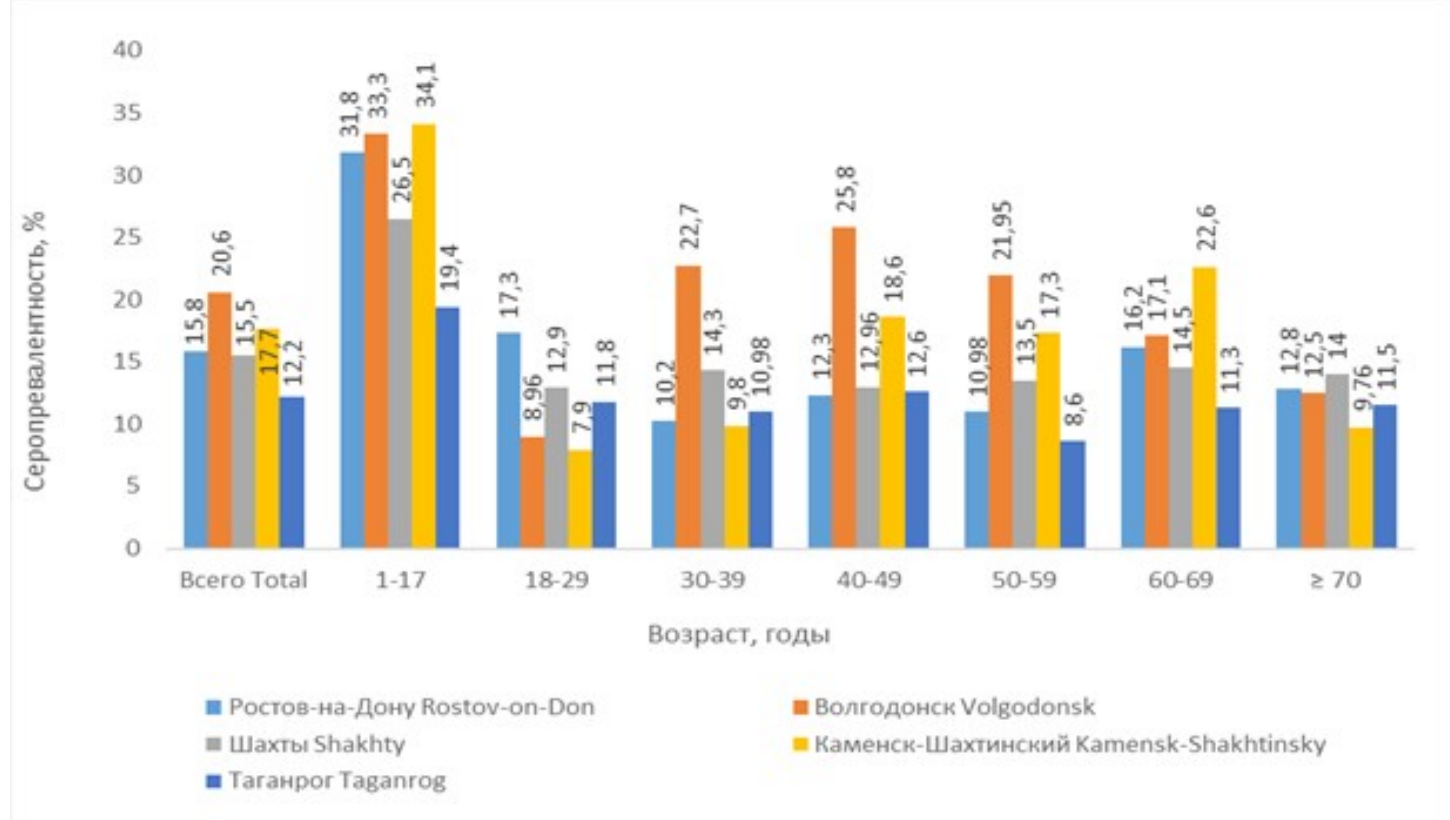

Рис. 1. Серопревалентность в разных возрастных группах населения городских округов Ростовской области к SARS-CoV-2

Figure 1. Seroprevalence in different age groups of the population of urban districts of the Rostov region to SARS-CoV-2. Y-axis - seroprevalence, \%; X-axis - age, years

В связи с существенным отличием числа положительных проб среди детей от других возрастных категорий мы разделили эту группу на три подгруппы: 1-6 лет, 7-13 лет, 14-17 лет. Как следует из представленных данных, наибольший уровень серопозитивности выявлен среди детей в возрасте от 1-6 и 7-13 лет. В то же время наибольшее число лабораторно подтвержденных случаев COVID-19 в Ростовской области зарегистрировано у лиц в возрасте 50-59 лет, а доля положительных в ПЦР лиц в возрасте 1-17 лет составляет около 7 \%. Выявление высокого процента серопозитивных проб среди 
детей может быть обусловлено либо бессимптомным носительством, и как следствие, отсутствием обращений в медицинские организации и обследования методом ПЦР, либо возможностью перекрестных реакций с другими коронавирусами. Данный факт, несомненно, требует дальнейшего изучения.

Доля IgG-положительных образцов у лиц старше 70 лет была наиболее низкой по сравнению с остальными возрастными группами $(12,5 \pm 3,3 \%)$, что в совокупности с высокой частотой хронических заболеваний сердечно-сосудистой системы у этой группы населения и повышенного риска развития тяжелого течения коронавирусной болезни свидетельствует о необходимости организации и проведения систематической специфической и неспецифической профилактики COVID-19 среди пожилого населения.

Достоверных гендерных различий в уровне серопревалентности не установлено,

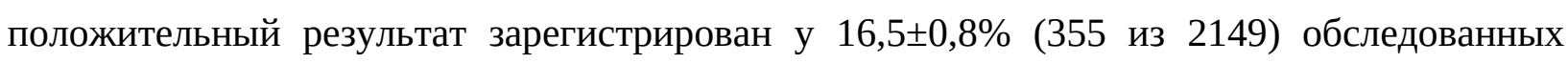
женщин и $16,6 \pm 1,24 \%$ (149 из 899) мужчин (р>0,05). При анализе результатов исследования среди разных социальных и профессиональных групп установлено, что наибольший уровень серопозитивности выявлен среди дошкольников $(33,6 \pm 4,4 \%)$, учащихся $(29,3 \pm 2,5 \%)$, служащих $(17,3 \pm 1,5 \%)$, работников образования $(15,3 \pm 2,2 \%)$ (таблица 3). Среди остальных профессиональных групп доля положительных проб составляла от $11,5 \pm 2,3 \%$ до $18,2 \pm 5,2 \%$. Обращает на себя внимание факт относительно невысокого числа серопозитивных лиц среди медицинских работников $(12,5 \pm 1,7 \%)$, несмотря на высокий риск контакта с носителями вируса и больными COVID-19, что может быть обусловлено достаточным уровнем подготовки по вопросам соблюдения требований биологической безопасности в медицинских организациях.

При анкетировании волонтеры указывали информацию о соблюдении режима самоизоляции в связи с распространением новой коронавирусной инфекции. Статистически достоверных отличий в показателях серопревалентности среди лиц в возрасте старше 18 лет, находящихся на самоизоляции, и продолжающих работать не

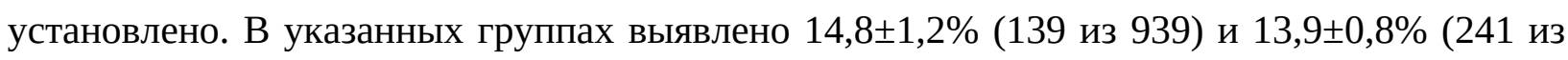
1705) положительных проб, соответственно (p>0,05).

В программе по оценке популяционного иммунитета приняли участие жители пяти городских округов Ростовской области, численность населения которых составляет 44,6\% от общего числа жителей области (табл. 2). При выборе городов Ростовской области для проведения исследования учитывали не только численность и плотность населения, но и площадь городских округов, наличие крупных предприятий, логистические связи с Кавказом, югом и центром России, миграцию из других регионов страны и населенных пунктов области. 
Заболеваемость COVID-19 в городских округах Ростовской области

Incidence of COVID-19 in urban districts of the Rostov region

\begin{tabular}{|c|c|c|c|c|}
\hline $\begin{array}{l}\text { Территория } \\
\text { Territory }\end{array}$ & $\begin{array}{l}\text { Количество } \\
\text { лабораторно } \\
\text { подтвержденных } \\
\text { случаев COVID-19 } \\
\text { (на 23.06.2020 г.) } \\
\text { The number of cases } \\
\text { COVID-19 } \\
\text { confirmed by } \\
\text { laboratory testing } \\
\text { (on 23.06.2020 г.) }\end{array}$ & $\begin{array}{l}\text { Численность } \\
\text { населения } \\
\text { (на 01.01.2020 г.) } \\
\text { Population } \\
\text { number } \\
\text { (on 01.01.2020 г.) }\end{array}$ & $\begin{array}{l}\text { Интенсивный } \\
\text { показатель } \\
\text { заболеваемос } \\
\text { ти, \%о0о0 } \\
\text { (на 23.06.2020 } \\
\text { г.) } \\
\text { Incidence, } \\
\text { \%o000 (on } \\
\text { 23.06.2020) }\end{array}$ & $\begin{array}{l}\text { Серопревале } \\
\text { нтность, \% } \\
(\mathrm{M} \pm \mathrm{m}) \\
\text { Seroprevalenc } \\
\text { е, \% } \\
(\mathrm{M} \pm \mathrm{m})\end{array}$ \\
\hline $\begin{array}{l}\text { г. Ростов-на-Дону } \\
\text { Rostov-on-Don }\end{array}$ & 2836 & 1133307 & 250,24 & $16,1 \pm 1,0$ \\
\hline $\begin{array}{l}\text { г. Волгодонск } \\
\text { Volgodonsk }\end{array}$ & 139 & 171952 & 80,84 & $21,4 \pm 1,8$ \\
\hline $\begin{array}{l}\text { г. Каменск- } \\
\text { Шахтинский } \\
\text { Kamensk-Shakhtinsky }\end{array}$ & 174 & 88319 & 197,01 & $18,3 \pm 2,1$ \\
\hline $\begin{array}{l}\text { г. Таганрог } \\
\text { Taganrog }\end{array}$ & 172 & 248664 & 69,17 & $12,2 \pm 1,4$ \\
\hline $\begin{array}{l}\text { г. Шахты } \\
\text { Shakhty }\end{array}$ & 469 & 231646 & 202,46 & $15,5 \pm 1,9$ \\
\hline
\end{tabular}

По административным территориям области наибольшая доля положительных проб выявлена в городе Волгодонске, наименьшая - в г. Таганроге, что соответствует наименьшему, из числа включенных в исследование административных территорий области, уровню заболеваемости (69,17 на 100 тыс. населения). В связи с этим, оценивали соотношение заболеваемости и серопозитивности в крупнейших населенных пунктах Ростовской области. Расчет провели по методу ранговой корреляции Спирмена. Рассчитанный коэффициент ранговой корреляции составил 0,1 , пороговое значение равно 2,4. Таким образом, корреляционная связь между сравниваемыми показателями заболеваемости и серопревалентности не доказана (рис. 1). Вместе с тем, следует подчеркнуть, что объем сравниваемых данных невелик и не дает оснований для достоверного вывода.

Одной из причин, которые могут оказать влияние на уровень серопревалентности в городах, Ростовской области, участвовавших в проекте, могут быть особенности сероконверсии в разных возрастных группах (рис. 1). 
Распределение серопревалентности по возрастным группам в сравниваемых городах в целом соответствует среднеобластному уровню (табл. 2) с некоторыми особенностями. Так, наименьший уровень сероконверсии среди детей отмечен в Таганроге и Шахтах. В возрастных группах 30-39, 40-49 и 50-59 лет наибольшая доля серопревалентных лиц приходится на Волгодонск, который по этому показателю лидирует и в целом по области. На данном этапе сложно дать объяснение полученным результатам. Вероятно, потребуются дополнительные исследования эпидемиологической и экологической направленности.

Важное значение на результаты формирования коллективного иммунитета и важнейшего его фактора - сероконверсии может оказать социальный и/или профессиональный фактор; и это не только лица пожилого и старческого возраста, но и работники здравоохранения, социальных служб, торговли, имеющие высокий риск контакта с потенциальными носителями вируса SARS-CoV-2 [9, 10]. Исследование серопревалентности в различных социально-профессиональных группах показало неоднозначные результаты (табл. 3).

Таблица 3/ Table 3

\section{Серопревалентность к SARS-CoV-2 в разных профессиональных} и социальных группах населения

Seroprevalence to SARS-CoV-2 across different occupational and social groups

\begin{tabular}{|c|c|c|c|}
\hline \multirow[t]{2}{*}{$\begin{array}{l}\text { Группа } \\
\text { Group }\end{array}$} & \multirow{2}{*}{$\begin{array}{l}\text { Количество } \\
\text { исследованных } \\
\text { проб } \\
\text { The number of } \\
\text { examined samples }\end{array}$} & \multicolumn{2}{|c|}{$\begin{array}{l}\text { Из них IgG+ к SARS-CoV-2 } \\
\text { Of these, IgG+ to SARS-CoV-2 }\end{array}$} \\
\hline & & $\begin{array}{l}\text { абс. } \\
\text { abs. }\end{array}$ & $\%, \mathrm{M} \pm \mathrm{m}$ \\
\hline $\begin{array}{l}\text { Служащие } \\
\text { Office workers }\end{array}$ & 631 & 109 & $17,3 \pm 1,5$ \\
\hline $\begin{array}{l}\text { Пенсионеры } \\
\text { Retirees }\end{array}$ & 501 & 63 & $12,6 \pm 1,5$ \\
\hline $\begin{array}{l}\text { Медицинские работники } \\
\text { Medical personnel }\end{array}$ & 360 & 45 & $12,5 \pm 1,7$ \\
\hline $\begin{array}{l}\text { Работники образования } \\
\text { Education workers }\end{array}$ & 268 & 41 & $15,3 \pm 2,2$ \\
\hline $\begin{array}{l}\text { Безработные } \\
\text { Unemployed }\end{array}$ & 212 & 29 & $13,7 \pm 2,4$ \\
\hline $\begin{array}{l}\text { ИП и самозанятые } \\
\text { Businessmen }\end{array}$ & 212 & 28 & $13,2 \pm 2,3$ \\
\hline $\begin{array}{l}\text { Рабочие производств } \\
\text { Factory workers }\end{array}$ & 200 & 23 & $11,5 \pm 2,3$ \\
\hline $\begin{array}{l}\text { Работники торговли } \\
\text { Sellers }\end{array}$ & 110 & 16 & $14,5 \pm 3,4$ \\
\hline $\begin{array}{l}\text { Работники сферы услуг } \\
\text { Service employees }\end{array}$ & 65 & 8 & $12,3 \pm 4,1$ \\
\hline Учащиеся & 321 & 94 & $29,3 \pm 2,5$ \\
\hline
\end{tabular}




\begin{tabular}{|l|c|c|c|}
\hline Students & & & \\
\hline $\begin{array}{l}\text { Дошкольники } \\
\text { Preschool children }\end{array}$ & 113 & 38 & $33,6 \pm 4,4$ \\
\hline $\begin{array}{l}\text { Прочие } \\
\text { Other }\end{array}$ & 55 & 10 & $18,2 \pm 5,2$ \\
\hline
\end{tabular}

Как уже отмечено выше, набольшая доля серопревалентных лиц относится к группам дошкольников и учащихся. Уровень сероконверсии среди медицинских работников, напротив, не показал сколько-нибудь значимого роста, зато среди работников образования отмечен достоверный рост доли сероположительных лиц по сравнению с медицинскими работниками $(\mathrm{p}<0,05)$. Низкая доля серопревалентных лиц среди пенсионеров вероятно связана с меньшей мобильностью этой группы и сопутствующей этому меньшей вероятностью контакта с вирусом.

Согласно данным литературы значительная часть случаев заражения COVID-19 протекает бессимптомно [11], в то же время противоречивы данные о роли гуморального иммунитета при новой коронавирусной инфекции и его продолжительности. В связи с этим был проведен анализ результатов исследования на антитела IgG к SARS-CoV-2 у лиц, переболевших или имевших контакт с больными COVID-19.

Из числа волонтеров 136 лиц имели контакт с больным COVID-19, при этом 31 из них были серопозитивными, что составляет 22,8土3,6\%. Выявлены статистически достоверные отличия по сравнению с группой лиц, не имевших контакта с больными, в которой доля положительных результатов на антитела IgG к SARS-CoV-2 составила $16,2 \pm 0,7 \%$, $(\mathrm{p}<0,05)$.

Среди волонтеров число лиц, переболевших COVID-19 с диагнозом, установленным в медицинских организациях, составило 25 человек (0,8\%), из них у 18 пациентов $(0,6 \%)$ наличие SARS-CoV-2 было лабораторно подтверждено. Антитела к

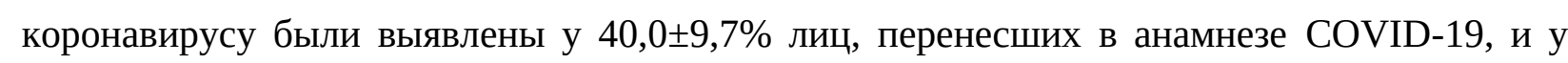
$38,9 \pm 11,5 \%$ в группе лиц с положительными результатами ПЦР. Следует отметить, что наиболее высокие показатели антительного ответа (индекс позитивности от 3,1 до 5,2) выявлен у волонтеров, с пневмонией в анамнезе (3 волонтера). Эти данные требуют дальнейшего изучения в связи с небольшим объемом выборки, однако согласуются с данными других исследований, свидетельствующих о зависимости иммунного ответа от тяжести клинических проявлений новой коронавирусной инфекции [9].

Основная часть волонтеров (83,5\%) на момент исследования не имела признаков OP3, и доля серопревалентных лиц среди них не отличалась от средней величины по всей популяции, $16,5 \pm 0,7 \%$ и $16,5 \pm 1,3 \%$, соответственно. В то же время среди волонтеров с

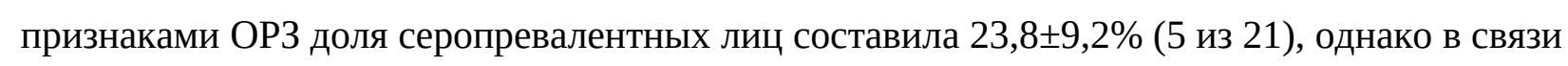


с малой выборкой не представляется возможным говорить о статистически достоверных различиях.

Для оценки распространенности бессимптомных форм в группе серопревалентных волонтеров вычисляли долю лиц, у которых отсутствовал в анамнезе диагноз COVID-19 или положительный ПЦР результат на SARS-CoV-2, и признаки OP3 на момент исследования (табл. 4). У жителей Ростовской области этот показатель составил 97,2士1,4\% (490 из 504), равномерно распределяясь по всем возрастным группам.

Таблица 4./Table4

Доля лиц с бессимптомным течением инфекции из общего числа серопозитивных жителей разных возрастных групп Ростовской области

The proportion of people with asymptomatic infection from the total number of seropositive volunteers of different age groups of the Rostov region

\begin{tabular}{|c|l|l|l|}
\hline $\begin{array}{l}\text { Возрастная групп, } \\
\text { лge group, years }\end{array}$ & $\begin{array}{l}\text { Число серо- } \\
\text { позитивных } \\
\text { волонтеров } \\
\text { Number of } \\
\text { seropositive } \\
\text { volunteers }\end{array}$ & $\begin{array}{l}\text { Число серопозитивных } \\
\text { волонтеров с бессимп- } \\
\text { томным течением } \\
\text { The number of } \\
\text { asymptomatic seropositive } \\
\text { volunteers }\end{array}$ & $\begin{array}{l}\text { Доля серопозитивных } \\
\text { волонтеров с } \\
\text { бессимптомным течением, } \\
\text { \%, M } \pm \text { m } \\
\text { The proportion of } \\
\text { asymptomatic seropositive } \\
\text { volunteers, } \%, \text { M } \pm \text { m }\end{array}$ \\
\hline $1-17$ & 124 & 123 & $99,2 \pm 0,8$ \\
\hline $18-29$ & 53 & 51 & $96,2 \pm 2,6$ \\
\hline $30-39$ & 58 & 57 & $98,3 \pm 1,7$ \\
\hline $40-49$ & 82 & 77 & $93,9 \pm 2,6$ \\
\hline $50-59$ & 64 & 61 & $95,3 \pm 2,6$ \\
\hline $60-69$ & 74 & 73 & $98,6 \pm 1,4$ \\
\hline$\geq 70$ & 49 & 490 & $98,0 \pm 2,0$ \\
\hline Всего/Total & 504 & & $97,2 \pm 0,7$ \\
\hline
\end{tabular}

\section{Заключение}

Полученные данные свидетельствуют о начале формирования популяционного иммунитета к SARS-CoV-2 среди жителей Ростовской области, однако, установленный уровень популяционного иммунитета (16,5 \%, данные на июнь 2020 г.) не способен оказать существенного влияния на динамику и интенсивность эпидемического процесса COVID-19 в Ростовской области, что обусловливает необходимость организации и проведения специфической профилактики новой коронавирусной инфекции среди населения. Высокий уровень гуморального иммунитета к SARS-CoV-2 на фоне низких показателей заболеваемости у лиц в возрасте от 1 до 17 лет может свидетельствовать о доминировании бессимптомных форм болезни среди данной возрастной группы. 


\section{ЛИТЕРАТУРА}

1. Tyrrell D.A., Bynoe M. L. Cultivation of a novel type of common-cold virus in organ cultures. Br Med. J. 1965; 1(5448): 1467-1470. DOI: 10.1136/bmj.1.5448.1467.

2. Yang Y., Peng F., Wang R., Guan K., Jiang T., Xu G., Sun J., Chang C. The deadly coronaviruses: The 2003 SARS pandemic and the 2020 novel coronavirus epidemic in China. Autoimmun. 2020; 109: 102-434. DOI: 10.1016/j.jaut.2020.102434.

3. Middle East respiratory syndrome coronavirus (MERS-CoV), WHO-EM/CSR/254/E/2019. [Электронный ресурс]. URL: http://www.who.int/emergencies/mers-cov/en/ (дата обращения 04.08.20).

4. Заявление Генерального директора ВОЗ по итогам совещания Комитета ММСП по чрезвычайной ситуации в связи с новым коронавирусом (2019-nCoV) от 30 января 2020 г. [Электронный ресурс]. URL: https:/www.who.int/dg/speeches/detail/who-director-generals-statement-on-ihr-emergency-committee-on-novel-coronavirus-(2019-ncov) (дата обращения 04.08.20 г.).

5. Randolph H.E., Barreiro L.B. Herd immunity: understanding COVID-19. Immunity. 2020; 52(5): 737-741. DOI: 10.1016/j.immuni.2020.04.012.

6. Anderson R.M., May R.M. Vaccination and herd immunity to infectious diseases. Nature. 1985; 318(6044): 323-9. DOI: 10.1038/318323a0.

7. Delamater P.L., Street E.J., Leslie T.F., Yang Y.T., Jacobsen K.H. Complexity of the basic reproduction number $\left(\mathrm{R}_{0}\right)$. Emerg. Infect. Dis. 2019; 25:1-4. DOI: 10.3201/eid2501. 171901.

8. Newcombe R.G. Two-sided confidence intervals for the single proportion: comparison of seven methods. Stat Med. 1998; 17(8): 857-887. DOI: 10.1002/(sici)10970258(19980430)17:8<857::aid-sim777>3.0.co;2-e.

9. Huang A.T., Garcia-Carreras B., Hitchings M.D.T., Yang B., Katzelnick L.C., Rattigan S.M., Borgert B.A., Moreno C.A., Solomon B.D., Rodriguez-Barraquer I., Lessler J., Salje H., Burke D., Wesolowski A., Cummings D.A.T. A systematic review of antibody mediated immunity to coronaviruses: antibody kinetics, correlates of protection, and association of antibody responses with severity of disease. Version 1. medRxiv. Preprint. 2020 Apr 17. doi: 10.1101/2020.04.14.20065771.

10. Moscola J., Sembajwe G., Jarrett M., Farber B., Chang T., McGinn T., Davidson K.W.. Prevalence of SARS-CoV-2 Antibodies in Health Care Personnel in the New York City Area. JAMA. 2020 Aug 6:e2014765. doi: 10.1001/jama.2020.14765. 
11. Tian S., Hu N., Lou J., Chen K., Kang X., Xiang Z., Chen H., Wang D., Liu N., D. Liu, Chen G., Zhang Y., Li D., J. Li, Lian H., Niu S., Zhang L., Zhang J.Characteristics of COVID-19 infection in Beijing. J Infect. 2020; 80(4):401-406. DOI: 10.1016/j.jinf.2020.02.018. Epub 2020 Feb 27.

\section{References}

1. Tyrrell D.A., Bynoe M. L. Cultivation of a novel type of common-cold virus in organ cultures. Br Med. J. 1965; 1(5448): 1467- 1470. DOI: 10.1136/bmj.1.5448.1467.

2. Yang Y., Peng F., Wang R., Guan K., Jiang T., Xu G., Sun J., Chang C. The deadly coronaviruses: The 2003 SARS pandemic and the 2020 novel coronavirus epidemic in China. Autoimmun. 2020; 109: 102-434. DOI: 10.1016/j.jaut.2020.102434.

3. Middle East respiratory syndrome coronavirus (MERS-CoV), WHO-EM/CSR/254/E/2019. (Cited 04 Aug 2020). [Internet]. Available from: http://www.who.int/emergencies/mers-cov/en/

4. WHO Director-General's statement on IHR Emergency Committee on Novel Coronavirus (2019-nCoV) from January 30, 2020. (Cited 04 Aug 2020). [Internet]. Available from: https://www.who.int/dg/speeches/detail/who-director-general-s-statement-on-ihremergency-committee-on-novel-coronavirus-(2019-ncov).

5. Randolph H.E., Barreiro L.B. Herd immunity: understanding COVID-19. Immunity. 2020; 52(5): 737-741. DOI: 10.1016/j.immuni.2020.04.012.

6. Anderson R.M., May R.M. Vaccination and herd immunity to infectious diseases. Nature. 1985; 318(6044): 323-9. DOI: 10.1038/318323a0.

7. Delamater P.L., Street E.J., Leslie T.F., Yang Y.T., Jacobsen K.H. Complexity of the basic reproduction number $\left(\mathrm{R}_{0}\right)$. Emerg. Infect. Dis. 2019; 25:1-4. DOI: 10.3201/eid2501. 171901.

8. Newcombe R.G. Two-sided confidence intervals for the single proportion: comparison of seven methods. Stat Med. 1998; 17(8): 857-887. DOI: 10.1002/(sici)10970258(19980430)17:8<857::aid-sim777>3.0.co;2-e.

9. Huang A.T., Garcia-Carreras B., Hitchings M.D.T., Yang B., Katzelnick L.C., Rattigan S.M., Borgert B.A., Moreno C.A., Solomon B.D., Rodriguez-Barraquer I., Lessler J., Salje H., Burke D., Wesolowski A., Cummings D.A.T. A systematic review of antibody mediated immunity to coronaviruses: antibody kinetics, correlates of protection, and association of antibody responses with severity of disease. Version 1. medRxiv. Preprint. 2020 Apr 17. doi: 10.1101/2020.04.14.20065771. 
10. Moscola J., Sembajwe G., Jarrett M., Farber B., Chang T., McGinn T., Davidson K.W.. Prevalence of SARS-CoV-2 Antibodies in Health Care Personnel in the New York City Area. JAMA. 2020 Aug 6:e2014765. doi: 10.1001/jama.2020.14765.

11. Tian S., Hu N., Lou J., Chen K., Kang X., Xiang Z., Chen H., Wang D., Liu N., D. Liu, Chen G., Zhang Y., Li D., J. Li, Lian H., Niu S., Zhang L., Zhang J.Characteristics of COVID-19 infection in Beijing. J Infect. 2020; 80(4):401-406. DOI: 10.1016/j.jinf.2020.02.018. Epub 2020 Feb 27. 